
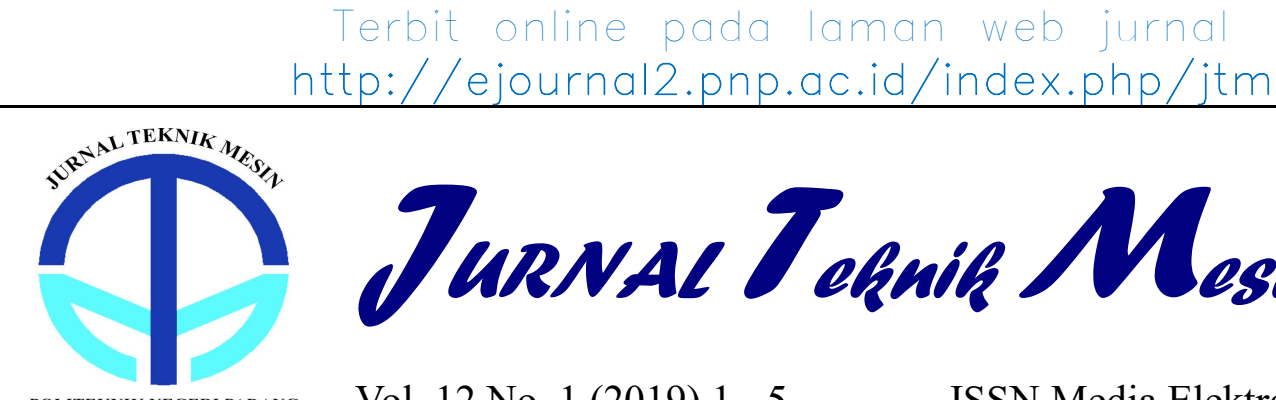

JuRnal Toguili Mesin

POLITEKNIK NEGERI PADANG

Vol. 12 No. 1 (2019) 1 - 5

ISSN Media Elektronik: 2655-5670

\title{
Pengujian Kincir Air Hidrokinetik Undershoot Di Irigasi Limau Manis Padang \\ Ruzita Sumiati ${ }^{1}$, Fardinal $^{2}$, Nusyirwan ${ }^{3}$, Adriansyah $^{4}$, Robby Novrizal ${ }^{5}$ \\ ${ }^{12345}$ Jurusan Teknik Mesin, Politeknik Negeri Padang \\ ruzita.sumiati@gmail.com
}

\begin{abstract}
Abstrac
The power produced by a hydrokinetic turbine depends on the interaction between the rotor and water. Therefore, the optimal rotor geometry must be designed and built to capture maximum water energy and convert it into usable energy. Hydropower is one of the potential renewable energy that can contribute to the need for electricity. Hydropower generator is pollution free so this generator can answer environmental problems and the availability of renewable energy sources. The aim to be achieved in this study is to produce a turbine hydropower with good performance if it operates on an irrigation channel and is applied as a power plant. This research was developed to get the right specifications for the use of hydrokinetic turbines in the irrigation canal area. There are several methods carried out in the design of hydrokenetic turbines, namely by designing blades based on the shape of water flow, repairing the transmission system, and selecting the right generator. In this study, we tested the sweet lemon irrigate applied and tested in the area of Padang Sumbar Sweet Limes Pauh, the results obtained were that the turbine can produce power of about 12.6 watts.
\end{abstract}

Keyword: Hydrokinetic, Renewable energy, Hydropower, undershoot

\begin{abstract}
Abstrak
Daya yang dihasilkan turbin hidrokinetik tergantung pada interaksi antara rotor dan air. Oleh karena itu, geometri rotor yang optimal harus dirancang dan dibangun untuk menangkap energi air maksimum dan mengubahnya menjadi energi yang dapat digunakan. Hydropower merupakan salah satu potensi energi terbarukan yang dapat memberikan kontribusi terhadap kebutuhan energi listrik. Pembangkit hydropower bebas polusi maka pembangkit ini dapat menjawab masalah lingkungan hidup dan ketersediaan sumber energy yang sifatnya dapat diperbaharui (renewable). Tujuan yang hendak dicapai pada penelitian ini adalah dihasilkan sebuah turbine hydropower dengan performance yang baik jika beroperasi pada saluran irigasi dan diaplikasikan sebagai pembangkit listrik. Penelitian ini dilakukan pengembangan untuk mendapapatkan spesifikasi yang tepat bagi pemanfaatan turbin hidrokinetik di area saluran irigasi. Ada beberapa metoda yang dilakukan dalam perancangan turbine hidrokenetik yaitu dengan mendisain sudu berdasarkan bentuk aliran air, perbaikan system transmisi, dan pemilihan generator yang tepat. Pada penelitian ini diuji coba diirigasi limau manis diaplikasikan dan diuji coba di daerah Limau Manis Pauh Padang Sumbar, Hasil yang didapat yaitu turbin dapat menghasilkan daya sekitar 12,6 watt.
\end{abstract}

Keyword: Hidrokinetik, Renewable energi, Hydropower, undershoot

\section{Pendahuluan}

Seiring dengan makin meningkatnya gaya hidup masyarakat dan teknologi yang makin meningkat diiringi dengan meningkatnya kebutuhan energi dari tahun ketahun. Untuk pemenuhan kebutuhan energi pada umumnya bersumber dari energi fosil dimana energi ini lama kelamaan akan habis karena sifatnya tidak dapat diperbaharui. Energi terbarukan kini menjadi kebutuhan yang telah diperhitungkan untuk menyelamatkan dunia dari krisis energi. Berdasarkan data Direktorat Energi Baru-Terbarukan dan Konservasi Energi, Kementerian Energi dan Sumber Daya Mineral (ESDM), peningkatan konsumsi energi Indonesia beberapa tahun belakangan ini mencapai tujuh persen per tahun. Untuk memenuhi kebutuhan 
itu, tak cukup hanya dengan mengandalkan energi fosil [2]

Sebagai mana yang kita ketahui sumber energi fosil sifatnya non renewable jika kita tetap bertahan hanya menggunakan energi fosil sebagai sumber energi maka suatu saat sumber energi akan habis. Kemudian pemakaian energi listrik yang bersumber dari fosil juga berefek pada peningkatan kadar emisi (CO2) di udara sehingga terjadinya efek rumah kaca. Efek dari keberadaan rumah kaca kini telah dapat dirasakan yaitu peningkatan temperatur di bumi. Peningkatan temperatur ini menyebabkan efek lanjutan seperti mencairnya es di kutub, kenaikan muka air laut, menggangu pertanian dan secara tidak langsung akhirnya berdampak pada ekonomi suatu negara [3]. Kemudian fakta lain yang terlihat di Indonesia bahwa tarif dasar listrik selalu naik dari tahun ketahun yang membuat perekonomian makin merosot apalagi bagi masyarakat menengah ke bawah.

Berdasarkan latar belakang tersebut di atas ada dua hal yang seharusnya dilakukan secara simultan untuk menghadapi masalah tersebut: konservasi dan diversifikasi sumber energi. Jadi, melakukan usaha penghematan konsumsi energi dan kemudian pada saat yang sama, juga melakukan pencarian dan penggunaan secara intensif sumber energi terbarukan (renewable energi resources). Untuk mengatasi ancaman defisit energi di masa depan, pengembangan energi baru dan terbarukan (renewable energi) di Indonesia menjadi sebuah keniscayaan. Apalagi potensi yang dimiliki oleh Indonesia sangat berlimpah. Salah satunya adalah energi yang bersumber dari tenaga air. Potensi tenaga air di seluruh Indonesia diperkirakan sebesar 75684 MW. Potensi ini dapat dimanfaatkan untuk pembangkit tenaga listrik dengan kapasitas $100 \mathrm{MW}$ ke atas dengan jumlah sekitar 800 [4] Tenaga air memiliki peran yang penting karena dapat menghasilkan listrik skala besar maupun kecil. Pembangkit Listrik Tenaga Mikro Hidro yang memiliki skala kecil ternyata dapat menghasilkan sebanyak 115 MW pada 2018 [5].

Di Sumatera Barat banyak memiliki saluran irigasi dengan aliran air yang cukup deras. Alangkah baiknya saluran ini dimanfaatkan sebagai penghasil energy listrik sebagai upaya kita dalam mendukung program pemanfaatan energi terbarukan yang ramah lingkungan. Menurut Menke, pemanfaatan energi air dari sebuah irigasi dapat memenuhi sebanyak 5\% dari konsumsi listrik sebuah kota [6]. Saluran irigasi termasuk kepada tipe aliran yang memiliki head rendah yaitu kurang dari 1,5 m Bozhinova et al. (2013) mengulas tentang konversi tenaga air dengan head air yang rendah termasuk kepada skala mikrohidro [7]; menurut Muller, agar dapat memanfaatkan perbedaan head air, ada tiga tipe dasar kincir air dikembangkan 1). tipe overshoot air masuk ke kincir dari atas. Jenis kincir ini beroperasi pada perbedaan head 2,5 hingga $10 \mathrm{~m}$ dan laju aliran $0,1 \mathrm{~s} / \mathrm{d} 0,2 \mathrm{~m}^{3} / \mathrm{s} ; 2$ ) Breast wheels, jenis roda ini digunakan untuk perbedaan head $1,5 \mathrm{~s} / \mathrm{d}$ $4 \mathrm{~m}$ dan laju aliran 0,35 hingga $0,65 \mathrm{~m}^{3} / \mathrm{s} ; 3$ ) tipe undershot air memasuki kincir di bawah porosnya, digunakan untuk perbedaan head yang sangat kecil 0,5 hingga $2,5 \mathrm{~m}$. [8].

Meskipun pengunaan pembangkit listrik tenaga hidro ramah lingkungan, efisiensinya sangat bagus dan potensi untuk dikembangkan sangat besar di wilayah Indonesia terkusus untuk daerah Sumatera Barat Mengingat potensi yang sangat besar yang dimiliki oleh Sumatera Barat untuk pengembangan tenaga hidro peneliti mengangkat topik tentang pengembangan turbin hidrokinetik undershoot dan pengaplikasiannya. Tujuan yang hendak dicapai pada penelitian ini adalah dihasilkannya desain kincir air yang dapat beroperasi pada aliran air di saluran irigasi dan memiliki kinerja yang optimal sehingga mampu menghasilkan output yang dapat dimanfaatkan oleh masyarakat.

\section{Metode Penelitian}

Metode yang digunakan dalam penelitian ini adalah metoda praktis yaitu membuat disain kincir dan melakukanproses manufaktur setelah itu langsung dilakukan pengujian dilapangan. Diagram alir penelitian dapat dilihat pada Gambar 1.

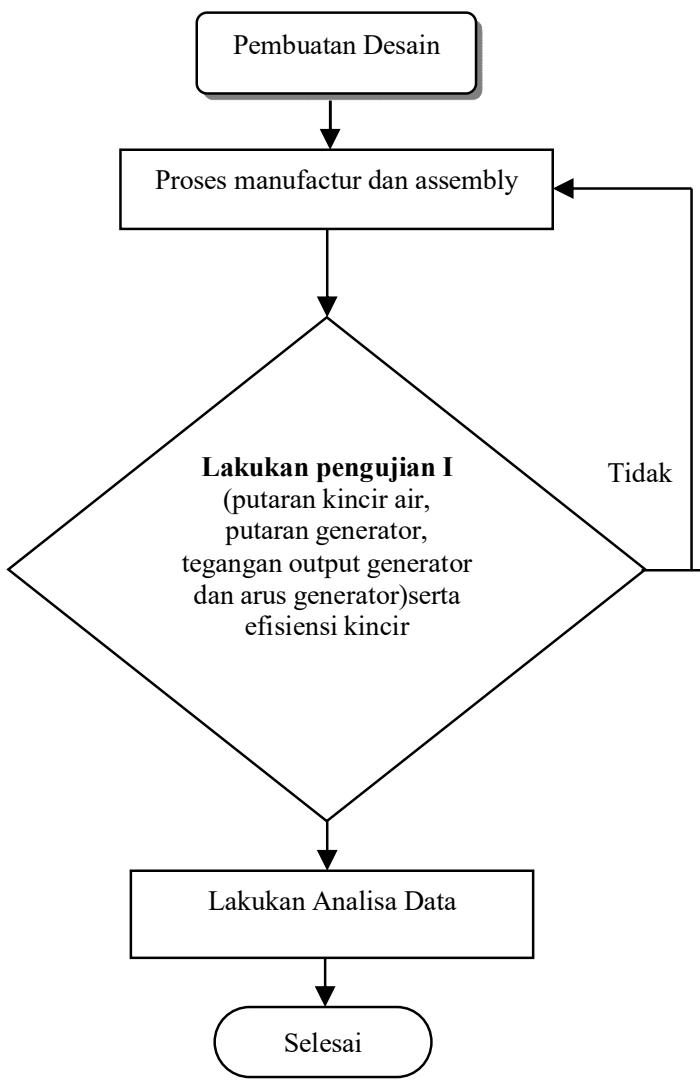

Gambar 1. Diagram Alir Penelitian

\section{Alat Pendukung Pengambilan Data}

1. Tachometer

Alat ini berfungsi untuk mengukur kecepatan putar pully kincir, khususnya jumlah putaran yang 
dilakukan oleh poros dalam satu satuan waktu. Cara penggunaannya adalah dengan menempelkan sensor pada bagian yang akan diukur rpmnya. Gambar 2.

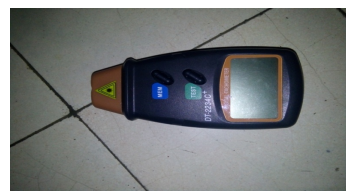

Gambar 2. Tachometer

2. Multitester

Sebagai pengukur tegangan, kuat arus dan tahanan yang dihasilkan generator Gambar 3.

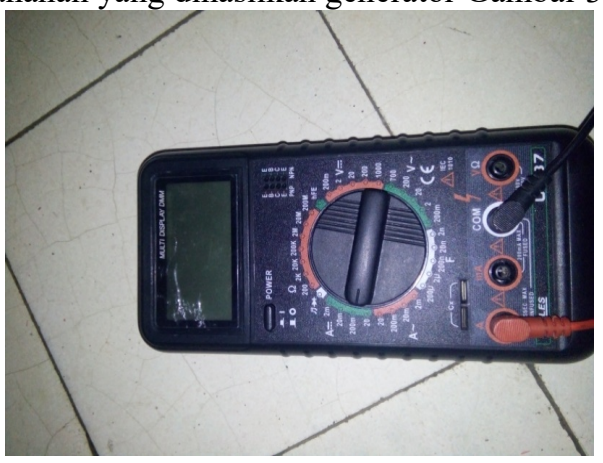

Gambar 3. Multitester digital

\section{Generator}

Generator Panasonic tipe MFA075LD2NSA Gambar 4. berfungsi untuk mengubah energi putaran poros menjadi energi listrik.

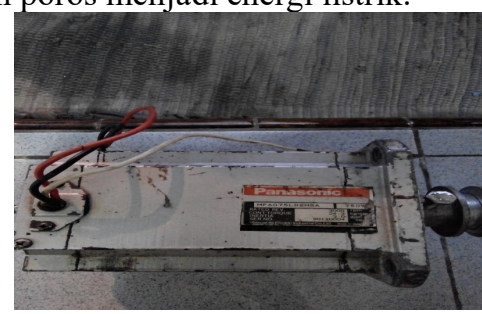

Gambar 4 Generator

Untuk melakukan survey data air adapun peralatan yang di butuhkan adalah

1. Stop watch

2. Bola pimpong

3. Meteran

4. Alat tulis

\section{Langkah pengambilan data kecepatan air}

Adapun cara yang digunakan dalam pengambilan data kecepatan air adalah metode apungan, yaitu :

1. Sediakan bola pimpong yang akan digunakan sebagai apungan.

2. Ukur jarak yang akan dilalui oleh apungan bola pimpong tersebut.

3. Siapkan stopwatch

4. Pada saat yang bersamaan jatuhkan bola pimpong kedalam air dan stopwatch dihidupkan.

5. Setelah bola pimpong melalui jarak yang telah ditentukan maka matikan stopwatch, catat hasil waktu yang ditunjukan stopwatch, lakukan percobaan ini sampai 7 kali.

Adapun langkah yang dilakukan untuk pengambilan data tinggi air dan lebar aliran air adalah sebagai berikut :

a. Menghitung tinggi air

Untuk melakukan pengukuran tinggi air kita dapat menggunakan meteran, lakukan pengukuran sebanyak 5 kali pada titik yang berbeda dan ambil rata-rata dari hasil pengukuran tersebut. Untuk lebih jelas perhatikan gambar 5 berikut:

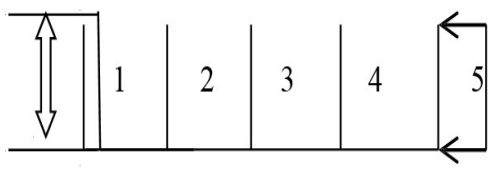

h

Gambar 5. Tinggi Air

b. Menghitung lebar aliran air

Untuk melakukan pengukuran lebar saluran air kita dapat menggunakan meteran, lakukan pengukuran sebanyak 5 kali pada bidang yang berbeda, untuk lebih jelas perhatikan gambar 6 berikut :

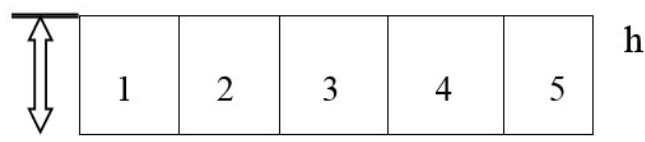

Gambar 6. Lebar Aliran Air

Adapun hasil pengukuran lebar saluran air adalah sebagai berikut

Tabel 1. Data Hasil Pengukuran Tinggi Air

\begin{tabular}{|c|c|c|}
\hline No. & Pengukuran & Hasil (m) \\
\hline 1 & Titik 1 & 1,18 \\
\hline 2 & Titik 2 & 1,17 \\
\hline 3 & Titik 3 & 1,19 \\
\hline 4 & Titik 4 & 1,17 \\
\hline 5 & Titik 5 & 1,19 \\
\hline & (jumlah) & 1,18 \\
\hline
\end{tabular}

Lebar Saluran Air

$$
\begin{gathered}
\text { Maka: } \mathrm{h}=27,9 \mathrm{~cm}=0,279 \mathrm{~m} \\
\mathrm{~L}=1,18 \mathrm{~m} \\
\begin{array}{c}
\boldsymbol{A}=\mathrm{H} \boldsymbol{x} \boldsymbol{L} \ldots \ldots \ldots \ldots \ldots \ldots \ldots \ldots \\
\mathrm{A}=0,279 \mathrm{~m} \boldsymbol{x} 1,18 \mathrm{~m} \\
A=32.922 \mathrm{~cm}^{2} \\
A=0,032 \mathrm{~m}^{2}
\end{array}
\end{gathered}
$$

Tabel 2. Spesifikasi kincir

\begin{tabular}{|c|l|c|}
\hline No & \multicolumn{1}{|c|}{ Jenis Pengukuran } & Satuan \\
\hline 1 & Diameter Kincir & $120 \mathrm{~cm}$ \\
\hline 2 & $\begin{array}{l}\text { Kecepatan rata-rata kincir } \\
(\mathrm{rpm})\end{array}$ & $28 \mathrm{Rpm}$ \\
\hline 3 & Massa Jenis Air & $1000 \mathrm{~kg} / \mathrm{m}^{3}$ \\
\hline
\end{tabular}




\begin{tabular}{|c|l|c|}
\hline 4 & Jumlah Sudu & 12 buah \\
\hline 5 & Panjang dan lebar sudu & $30 \mathrm{~cm} \mathrm{x} \mathrm{34cm}$ \\
\hline 6 & Gaya Kincir & $29,13 \mathrm{~N}$ \\
\hline
\end{tabular}

\section{Hasil dan Pembahasan}

\section{Pengambilan Data Air}

Air adalah suatu zat yang tidak bisa dimampatkan, karena sifatnya ini sehingga dapat dimanfaatkan sebagai sebuah energi yang dapat didaur ulang, oleh karena itu penulis harus bisa mengambil data yang dibutuhkan untuk pembuatan alat pemanfaatan energi air. Pengujian ini dilakukan didaerah Limau Manis, Padang, Sumatera Barat Gambar 5

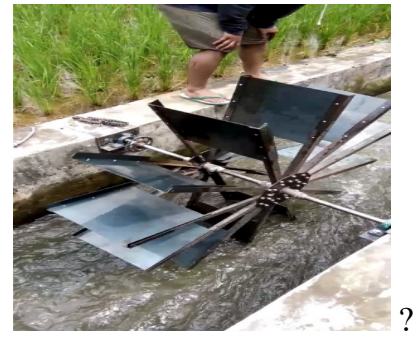

Gambar 7. Pengambilan data Kecepatan Air

Untuk mengetahui kecepatan air maka kita dapat menggunakan persamaan berikut :

$\mathrm{v}=\frac{s}{t}$

Dimana :

$\mathrm{v}=$ kecepatan $(\mathrm{m} / \mathrm{s})$

$\mathrm{s}=\operatorname{jarak}(\mathrm{m})$

$\mathrm{t}=$ waktu (s)

Tabel 3. DataPercobaan Kecepatan Air

\begin{tabular}{|c|c|c|c|}
\hline \multirow{2}{*}{ Percobaan } & \multicolumn{3}{|c|}{ Waktu (s) } \\
\cline { 2 - 4 } & Hari1 & Hari 2 & Hari3 \\
\hline 1 & 1,24 & 1,15 & 1,05 \\
\hline 2 & 1,87 & 1,50 & 1,1 \\
\hline 3 & 2,25 & 1,40 & 1,23 \\
\hline 4 & 1,65 & 1,50 & 1,44 \\
\hline 5 & 1,27 & 1,27 & 1,20 \\
\hline 6 & 2,04 & 1,48 & 1,45 \\
\hline 7 & 2,84 & 1,56 & 1,55 \\
\hline$\Sigma$ & 13,16 & 9,86 & 9,02 \\
\hline Rata-rata & 1,88 & 1,40 & 1,28 \\
\hline
\end{tabular}

Untuk menghitung debit air kita dapat menggunakan persamaan berikut :

$\mathrm{Q}=\mathrm{V}$. A

Dimana :

$\mathrm{Q}=$ Debit air $\left(\mathrm{m}^{3} / \mathrm{s}\right.$ atau $\left.\mathrm{L} / \mathrm{s}\right)$

$\mathrm{V}=$ Kecepatan air $(\mathrm{m} / \mathrm{s}) /$ rata-rata pada pengujian

$\mathrm{A}=$ Luas penampang saluran $\left(\mathrm{m}^{2}\right)$
Maka:

$$
\begin{aligned}
Q & =\mathrm{A} \times \mathrm{V} \\
Q & =0,032 \mathrm{~m}^{2} \times 2,68 \mathrm{~m} / \mathrm{s} \\
Q & =0,085 \mathrm{~m}^{3} / \mathrm{s} \\
& =85 \mathrm{Liter} / \mathrm{s}
\end{aligned}
$$

Jadi kecepatan rata-rata kincir air yang didapatkan selama pengujian adalah $28(\mathrm{rpm})$.

Adapun daya yang dihasilkan kincir dapat dihitung dengan persamaan sebagai berikut:

$$
\mathrm{Pk}=\mathrm{T} \frac{2 . \pi \cdot n}{60}
$$

Dimana :

$\mathrm{Pk}=$ daya kincir

$\mathrm{T}=$ torsi yang dihasilkankincir $(\mathrm{Nm})$

$\pi=$ ketetapan 3,14

$\mathrm{n}=$ putarankincir $(\mathrm{Rpm}) / \mathrm{rpm}$ rata-rata pada

$$
\begin{aligned}
\mathrm{Pk} & =17,48 \mathrm{~N} \cdot \mathrm{m} \frac{2 \cdot 3,14 \cdot 28}{60}=50,69 \mathrm{watt} \\
& =0,05069 \mathrm{kw}
\end{aligned}
$$

Ada pun torsi yang di hasilkankincir dapat dihitungdenganpersamaanberikut:

$$
\begin{aligned}
\mathrm{T} & =\mathrm{F} . \mathrm{R} \ldots \ldots \ldots \ldots \ldots \\
& =29,13 \text { N. } 0,6 \mathrm{~m} \\
& =17,48 \mathrm{~N} . \mathrm{m}
\end{aligned}
$$

Untuk menentukan tekanan air pada kincir kita dapat menggunakan persamaan berikut :

$$
\begin{aligned}
\mathrm{P} & =\frac{F}{\text { Aalir }} \ldots \ldots \ldots \ldots . . . . . \\
& =\frac{29,13 \mathrm{~N}}{0,32 \mathrm{~m} 2} \\
& =91,03 \mathrm{~N} / \mathrm{m}^{2}
\end{aligned}
$$

Water horse power merupakandaya yang dihasilkanoleh air akibat ketinggian dan kapasitas air.

$$
\begin{aligned}
& \text { WHP }=\rho . Q . g . h(\text { watt }) \ldots \ldots \ldots \ldots \ldots \ldots \ldots \ldots \ldots .(7) \\
& =1000 \mathrm{~kg} / \mathrm{m}^{3} .0,085 \mathrm{~m}^{3} .9,81 \mathrm{~m} / \mathrm{s} .0,27 \mathrm{~m} \\
& =0,22513 \mathrm{kw}
\end{aligned}
$$

Efisiensi merupakan perbandingan antara $\mathrm{Pk}$ dengan WHP.

$$
\begin{aligned}
\eta= & \frac{p k}{w h p} \cdot 100 \% \ldots \ldots \ldots . . . \\
& =\frac{50,69 w}{416,92 w} \times 100 \% \\
& =22,51 \%
\end{aligned}
$$

\section{Data Hasil Pengujian Kincir Air}

Setelah melakukan percobaan dan pengambilan data, maka didapatkan data yang selanjutnya akan diolah. Data hasil pengujian pada kincir air undershot didapatkan dari pengukuran arus yang dihasilkan oleh generator, tegangan yang dihasilkan generator 
serta rpm kincir dari pengukuran kecepatan putar kincir.

Pengujian terhadap daya yang dihasilkan generator melalui pengukuran tegangan dan arus keluaran generator:

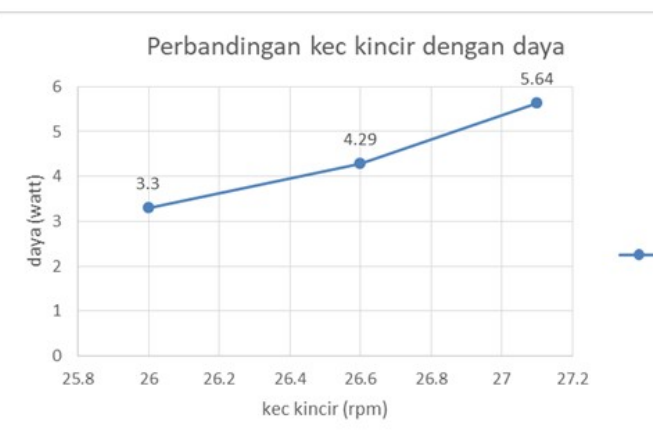

Gambar 8 Grafik Perbandingan Kec dengan Daya kec air 2,13 $\mathrm{m} / \mathrm{s}$

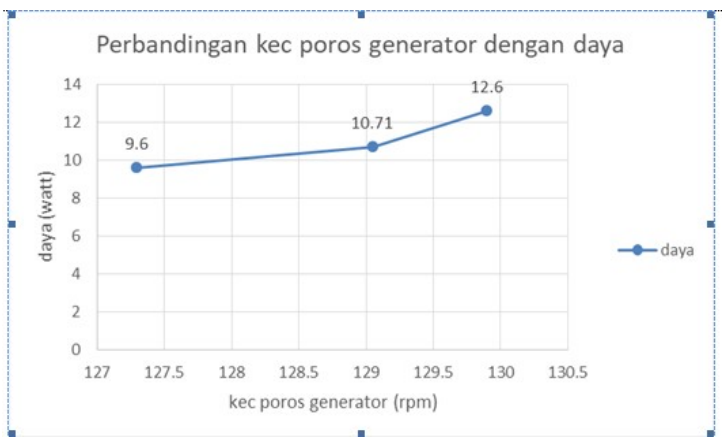

Gambar 9 Grafik perbandingan kec \& daya pada kec air 3,12m/s

\section{Kesimpulan}

Berdasarkan dari data, perhitungan dan pengujian dilapangan yang telah dilaksanakan, maka penulis dapat mengambil beberapa kesimpulan antara lain :
1. Berdasarkan data yang diperoleh dari lapangan maka didapatkan kecepatan air pada hari pertama sebesar $2,13 \mathrm{~m} / \mathrm{s}$, pada hari kedua 2,8 $\mathrm{m} / \mathrm{s}$, pada hari ketiga $3,12 \mathrm{~m} / \mathrm{s}$ dan debit air yang diperoleh sebesar 85 liter/s.

2. Pengujian terhadap daya yang dihasilkan generator melalui pengukuran tegangan dan arus keluaran dari generator. Daya didapatkan dari perkalian antara tegangan dan arus. Daya maksimum dari kincir air dengan tegangan $7 \mathrm{~V}$ dan arus 1,8 A yaitu sebesar 12,6 watt dengan putaran kincir tertinggi $30 \mathrm{rpm}$.

3. Berdasarkan perhitungan maka efisiensi dari kincir air diperoleh 22,51\%.

\section{Daftar Rujukan}

1. Energi Masa Depan. 2013. Suplemen Energi Terbarukan, majalah Tempo

2. Smith SJ, Edmonds J, Hartin CA, Mundra A, Calvin K 2015. Near-term acceleration in the rate of temperature change. Nat Clim Change; 5: 333-336

3. Koch, J U. Dayan, dan Mey Marom. 2015. Inventory of Emission of greenhouse Gases in Israel. Journal of Water, Air, \& Soil Polution, page 259-271

4. https://www.itb.ac.id/news/read/56825/home/prof-priyonosoetikno-indonesia-mempunyai-potensi-energi-baru-danterbarukan-yang-melimpah 12:55 9 april 2019

5. http://web.ipb.ac.id/ tepfteta/elearning/media/Energi\%20da n\%20Listrik\%20Pertanian/MATERI\%20WEB\%20ELP/Ba b\%20V\%20ENERGI\%20AIR/indexAir.htm 13.009 april 2019.

6. Menke, R., Abraham, E., Parpas, P., and Stoianov, I. 2016. Demonstrating, Demand Response From Water Distribution System Through Pump Scheduling, Appl. Energ., 170, 377387

7. Bozhinova, S., Kisliakov, D., Müller, G., Hecht, V., \& Schneider, S. 2013. Hydropower converters with head differences below $2.5 \mathrm{~m}$. Proceedings of the ICE-Energy 165.

8. Müller, G., \& Batten, W. M. J. 2010. Potential, performance limits and environmental effects of floating mills for energy generation in rivers. Proceedings of river flow 2010, International Conference on fluvial hydraulics, Braunschweig, September 8-10.

9. Ferial. 2016. Pemerintah Optimis Target Energi Terbarukan Tercapai. 